\title{
Emergency Governance and Preparedness to Respond
}

\author{
Zoran Nusev ${ }^{1}$ and Aleksandar Risteski ${ }^{2}$ \\ 1. Government Mobile Communications Branch, Government of Ontario, Osprey Blvd 6196, Mississauga L5N 5W4, Canada \\ 2. Department of Telecommunications Faculty of Electrical Engineering and Information Technologies, University of St. Cyril and \\ Methodius, Ruger Boskovic 18, Skopje 1000, Macedonia
}

\begin{abstract}
Every level of government (local, state and federal), every corporation and organization has an ultimate goal of preventing and being ready for the (un)accounted emergencies. Having the organizational policies in place, budget assigned makes it all that much easier to deal with these risks. The paper is focusing on the differences and alignments between Canada and Macedonia in their preparedness for the Emergencies. The goal is to analyze and use this information to further develop the standard operating procedures, governance and communications within which will provide better preparedness, management and prevention of loss of life and property.
\end{abstract}

Key words: Emergencies, risks, governance, SOP.

\section{Introduction}

We live in the information age. The real time collection and distribution of information, related to the potential and on-going emergencies is crucial to prevent and be properly prepared to deal with them. Countries across the world developed their own common systems which are or they're not the same within the region. This paper is going to focus on the differences and alignments between Canada (second biggest territory in the world) and Macedonia (one of the smaller territories in the world) in their preparedness for the Emergencies. The goal is to analyze and use this information to further develop the standard operating procedures, governance and communications within which will provide better preparedness, management and prevention of loss of life and property.

\section{Analysis}

\subsection{Canada}

Definition of an Emergency: "A present or

Corresponding author: Zoran Nusev, Ph.D., research fields: secure public safety communications and private mobile radio networks. imminent incident requiring the prompt coordination of actions, persons or property in order to protect the health, safety or welfare of people, or to limit damage to property or to the environment" [1].

Most emergencies are local in nature and are managed at the community or provincial/territorial level. The Federal Government can become involved where it has primary jurisdiction and responsibility as well as when requests for assistance are received due to capacity limitations and the scope of the emergency. However, certain risk factors increase the potential for catastrophes to transcend geographical or jurisdictional boundaries and to challenge the capacity of federal and provincial/territorial governments to manage emergencies. These risk factors include increased urbanization, critical infrastructure dependencies and interdependencies, terrorism, climate variability and change, scientific and technological developments (e.g., nanotechnologies), animal and human health diseases, and the increased movement of people and goods around the world.

The Emergency Management Act [2] defines emergency management as the prevention and mitigation of, preparedness for, response to, and recovery from emergencies. Under the Emergency 
Management Act, the Minister of Public Safety is responsible for coordinating the Government of Canada's response to an emergency. The FERP (federal emergency response plan) is the Government of Canada's "all-hazards" response plan.

The FERP is designed to harmonize federal emergency response efforts with those of the provinces/territorial governments, non-governmental organizations, and the private sector.

The Minister of Public Safety [3] is responsible for promoting and coordinating emergency management plans, and for coordinating the Government of Canada's response to an emergency. The Minister of Public Safety authorized the development of the FERP pursuant to the Department of Public Safety and Emergency Preparedness Act and the Emergency Management Act.

The FERP applies to domestic emergencies and to international emergencies with a domestic impact. This plan has both national and regional level components, which provide a framework for effective integration of effort both horizontally and vertically throughout the Federal Government.

Canada's risk environment includes the traditional spectrum of natural and human-induced hazards: wild-land and urban interface fires, floods, oil spills, the release of hazardous materials, transportation accidents, earthquakes, hurricanes, tornadoes, health or public health disorders, disease outbreaks or pandemics, major power outages, cyber incidents, and terrorism.

As part of the coordinating department, the role of Public Safety Canada's Operations Directorate is to manage and support each of the primary functions of the FERMS (federal emergency response management system) at the strategic level, and Public Safety Canada Regional Offices perform the same role at the regional level. In doing so, Public Safety Canada will work in cooperation with federal departmental representatives and other representatives to guide the integration of activities in response to emergencies.
The regional component of the FERMS has similar functions as the Government Operations Center when escalated.

The Public Safety Canada Communications Directorate coordinates emergency public communications activities for the Government of Canada between federal government institutions, with provincial/territorial partners, international partners, and with non-government organizations. The Communications Directorate also provides support and strategic public communications advice on issues relating to the public and media environment as part of each of the primary functions of the FERMS.

The FERMS is a comprehensive management system which integrates the Government of Canada's response to emergencies. It is based on the tenets of the Incident Command System and the Treasury Board Secretariat's Integrated Risk Management Framework.

This system provides the governance structure and the operational facilities to respond to emergencies. The FERMS can scale operations to the scope required by an emergency with the support and emergency response expertise of other federal government institutions. It also links national and regional levels of activity, creating both vertical and horizontal integration of effort within the Federal Government, and integrates federal emergency response actions with those of the provinces/territories.

The FERMS provides the mechanisms and processes to coordinate the structures, the capabilities, and the resources of federal government institutions, non-governmental organizations and the private sector into an integrated emergency response for all hazards.

The FERMS includes a coordinated system of public communications. Trained and experienced managers and staff from the Communications Directorate of Public Safety Canada provide support. The level of coordination is scaled to the scope of the emergency. Other national and regional government 
departments also provide support.

Public Safety Canada houses the Government Operations Center. It is the principal location from which Subject Matter Experts and Federal Liaison Officers from federal government institutions, non-governmental organizations, and the private sector perform the primary functions related to FERMS.

There are defined emergency response levels. The purpose for establishing and communicating emergency response levels with regard to a potential or occurring incident is to alert federal government institutions and other public and private sector emergency response partners that some action outside of routine operations, may, or will be required. The three response levels defined below are intended to provide a logical progression of activity from enhanced monitoring and reporting to an integrated federal response.

Level 1-Enhanced Reporting-response serves to focus attention upon a specific event or incident that has the potential to require an integrated response by the Federal Government.

Level 2-Risk Assessment and Planning-response requires a full understanding of an incident. As an incident unfolds and the requirement for a federal response becomes clearer, a risk assessment is conducted. This assessment, conducted in consultation with Subject Matter Experts, identifies vulnerabilities, aggravating external factors and potential impacts.

The assessment then guides the development of a strategic plan for an integrated response (if required). Subject Matter Experts are usually required during the development of risk assessments and contingency planning. Level 2 includes enhanced reporting.

Level 3-Coordination of Federal Response-The Government Operations Center serves as the coordination center for the federal response, and provides regular situation reports as well as briefing and decision-making support materials for Ministers and Senior Officials. As requests for information and assistance are received, they are assigned to those institutions with the applicable mandate and response capabilities to carry out and/or support the integrated federal response. The Federal Coordination Center is the focal point for Federal and Federal-Provincial/Territorial coordination during response. It supports and is supported by the Government Operations Center.

When an integrated response is required, all plans and arrangements for the federal response are escalated. Federal Liaison Officers are usually required to participate in the Government Operations Center throughout this level of escalation, whereas Subject Matter Experts from Primary and Supporting institutions will be requested to contribute to the on-going risk assessment and planning activities as required. Departmental emergency response plans are escalated and materiel and resources readied in anticipation of provincial or other requests for federal assistance, and the Government Operations Center maintains constant communication with those activated centers. Level 3 includes enhanced reporting along with risk assessments and planning as required.

Public Safety Canada integrates the federal component of an emergency response through the following functions:

- Operations;

- Situational awareness;

- Risk assessment;

- Planning;

- Logistics;

- Finance and administration.

The Planning Function develops objectives, courses of action, and strategic advanced plans for the Government of Canada based on information from the Risk Assessment Function. The management team consults with the Federal Coordinating Officer before approving the proposed objectives and courses of action. The following steps are taken in this phase:

- Contingency Planning;

- Incident Action Planning; 
- Incident Action Plan Task Matrix;

- Strategic Advance Planning.

Public Safety Canada in coordination with the supportive Ministries and Agencies has developed the Standard Operating Procedure Document, which can be used to report and collect relevant information regarding the emergencies. The document is used by all the Provinces and Territories in Canada.

\subsection{Macedonia}

Similar to the Canadian definition of emergency, Macedonia in coordination with the EU (European Union) and the countries in the region defined emergency as "Emergency is natural or manmade event, which can cause the loss of live and property big enough to cause further health and safety risks to the population. Natural and manmade emergencies are earthquakes, volcano activities, landslides, floods, droughts, environmental pollution, forest fires, dam collapses, health epidemics, nuclear/chemical /industrial catastrophes and airplane/train/ship accidents".

Compare to Public Safety Canada, National CMC (crisis management committee) [4] is the highest authority to plan, prevent and deal with emergencies. The CMC has the Management department which is the Government assigned body to lead CMC and the whole emergency management. The Committee consists of the Ministers of Internal Affairs, Health, Communications, Foreign Affairs and the Manager of the Risk Assessment division. If necessary, more members and SMEs could be invited to take part of the Committee. Additional members are opposition member of the National Assembly Security Committee and the member of the President's personal.

Risk Assessment division as the government body continuously monitors the situation on the terrain, defines possible risks and recommends measures to prevent them. This includes definition and execution of the early warning system and managing the emergency after the fact. Members of the division are the Directors of Public Safety, Intelligence Agency, CMC, Protection and Rescue Directorate, deputy Minister of Defense and the Intelligence Manager.

Risk Management Analysis are delivered to the CMC Management Group, Primer, National Assembly President and the President of the Republic.

As part of the Legislature, there is Crisis Management Act [5] put in place which is parallel to Emergency Management Act in Canada.

$\mathrm{CMC}$ and the Management Department are developed to provide plans and solutions, constant monitoring, following the situation on the ground, efficiency, resource management and situational awareness with the possible impact on the health and safety of the people of the Republic and the Republic itself.

During the emergencies, $\mathrm{CMC}$ will provide the continuity in the intra-agency relations, consultations and the crisis management coordination. CMC is responsible for the technical, organizational and administrative support, recommends the options and activities to resolve the emergencies, all covered under the crisis management legislature.

CMC has Sectors, Departments and Regional Offices. The following are the sectors in CMC:

- Administrative;

- Legal and Medium Communications;

- Financial;

- IT, Telecom and Support of the Warning System;

- International Collaborations and.

Regional Sector for Operations and Coordination with their respective boundaries is presented in Fig. 1.

Similar to the Canada, where Provinces and Territories have their own centers, Republic of Macedonia has 35 centers, that include 34 regional and one center dedicated to the city of Skopje. All of these centers are responsible to follow the situation, propose activities and solutions to mitigate the risks and resolve the emergency situations, for their respective areas. The information is collected and 


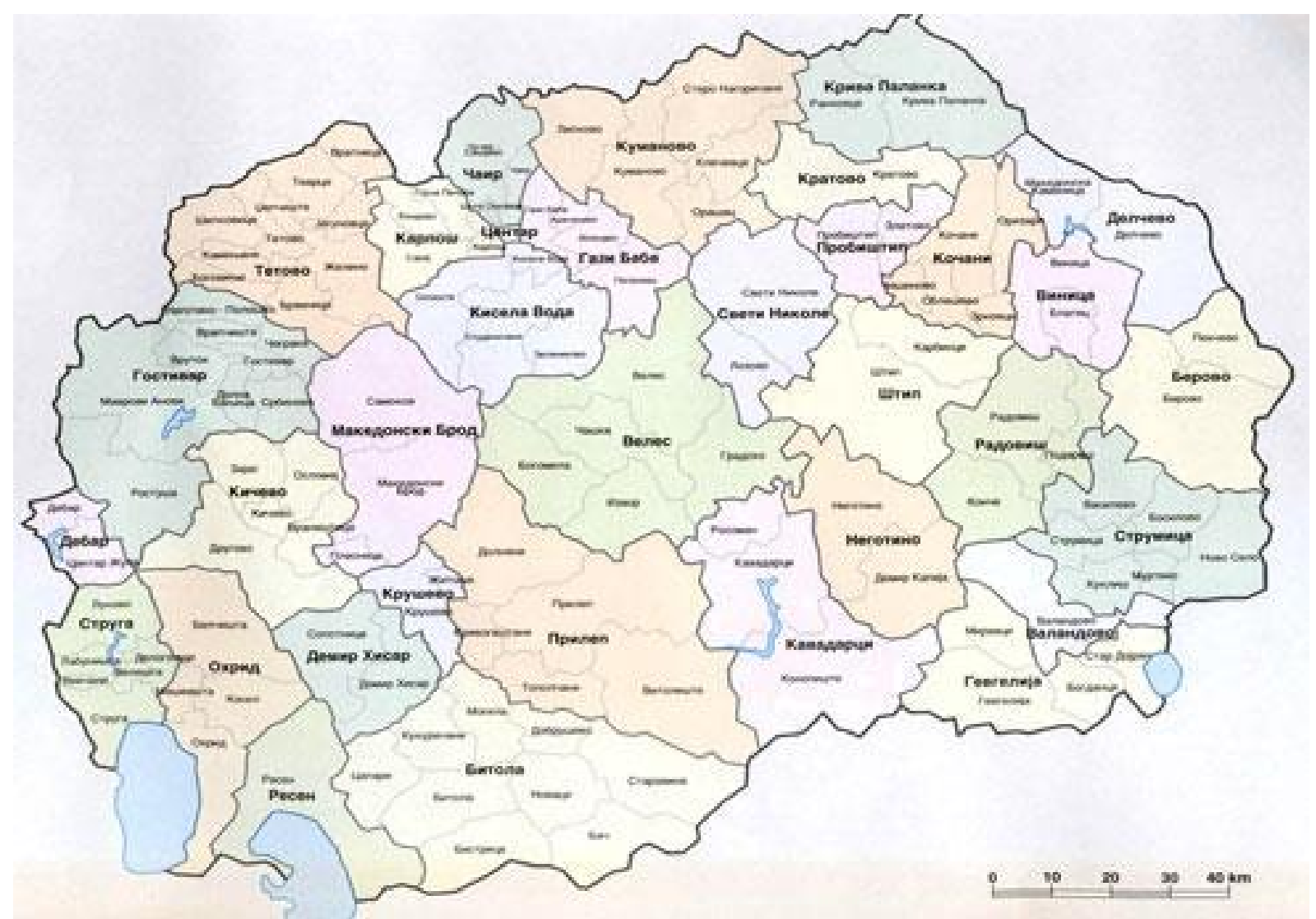

Fig. 1 Map of the Regional Centers in Macedonia.

analyzed in the main office in the CMC and communicated to all the affected regional centers. The regional centers are responsible to manage the emergencies as long as it is contained in their geographical areas and are no impact on to the neighboring regions. When the emergencies are affecting multiple regions, $\mathrm{CMC}$ main center is activated to provide full coordination of events.

International coordination is provided by the $\mathrm{CMC}$ and it is with UN regional offices, OBSE, EU, NATO, DPPI SEE [6] other countries CMCs (or equivalent), foreign Embassies, Red Cross, Red Crescent and other humanitarian organizations. In order to protect the peace and safety of the Republic of Macedonia, other international organizations and institutions can take part. In extreme situations, when the safety of the republic is threatened, Armed Forces can be recalled to provide all the support in preventing the emergencies spreading throughout the country and beyond. The involvement of the Armed forces, their capacity, role and responsibility, can be only approved by the President of the Republic as a Chief Commanding officer.

As part of the communications management, central phone services to be used to report any emergencies, risks and other accidents throughout the whole territory of RM, has been developed. This phone number is 195 and it is 24/7 operational. Furthermore, common European reporting number is 112 and for North America (Canada and USA) is 911. RM is working on the transition which will bring the country onto the same common platform within the EU.

The European emergency telephone number 112 was established by a decision of the European Council on 29 July 1991. With the Directive 2002/22/EC of the European Parliament and of the Council on universal service and users' rights relating to electronic communications networks and services 
(Universal Service Directive) the Member States of the European Union are obliged to implement the single European emergency number E-112. Article 40 of the Crisis Management Act-for the continuous and efficient execution of the works under the Article 37, the Centre is establishing a single communication-information system with a unique call number for calling in case of risks, hazards and other disasters throughout the country, 112.

SOPs (standard operational procedures) $[7,8]$ on prevention, mitigation and recovery of emergencies, has been developed in Macedonia and it is in alignment with the National SOP, in this case EU, UN, International Organization of Red Cross and Red Crescent Societies. The SOPs defines who is doing what, when and how:

Interoperability on national and international level:

- Unified terminology;

- Unified or compatible organized scheme;

- Unified approach to training and exercises (and certification);

- Compatibility of equipment;

- Unified operational procedures;

- Standard approach in shearing of information.

Training and education must have in order to be able to plan and execute emergency plans, policies and procedures. Protection and Rescue Act [9] is in place and educational procedures and mandates are in place for continuous public education of emergencies, communications, protections and rescue procedures. Public education about the awareness of catastrophes, are integrated as early as in the elementary educational programs, followed by work place continuous education.

\section{Conclusion}

As we can see, Republic of Macedonia has accomplished a lot to try and align the governance and preparedness models to better respond to emergencies. SOPs are in place and already in use during the current environmental emergencies in Macedonia. $\mathrm{CMC}$ is now a mature organization with more than 10 years of providing services to the public. In addition, the process of establishing the unified phone number (112) will align with the European Union Countries and with the countries in the region that would be involved in future joint projects.

\section{References}

[1] Federal Emergency Response Plan, Canada, January 2011.

[2] An Emergency Management Framework for Canada, $2^{\text {nd }}$ Edition, 2011.

[3] Public Safety Canada. https://www.publicsafety.gc.ca/index-eng.aspx, last accessed September 2015.

[4] Crisis Management Center, Republic of Macedonia. http://cuk.gov.mk/en/, last accessed September 2015.

[5] Crisis Management Act, Republic of Macedonia, No. 07-1537/a. Accessed April 22, 2005.

[6] DPPI SEE, Disaster Preparedness and Prevention Initiative for South Eastern Europe. http://www.dppi.info/members/macedonia, last accessed September 2015.

[7] Protection and Rescue Directorate, Government of Republic of Macedonia. http://www.dzs.gov.mk/, last accessed September 2015.

[8] Emergency Plan of Action (EPoA), Republic of Macedonia. Accessed August 2015.

[9] Protection and Rescue Act, Republic of Macedonia. http://www.macefdrr.gov.mk, Accessed June 102004. 
Zoran Nusev is a Network Radio Engineer at the Ontario's Justice Technology Services with the Ministry ofCommunity Safety and Correctional Services. He has extensive knowledge of the Public Safety Agency requirements and expert in Military Communications, as a direct result of being part of them for the past 25 years. He started as Military Telecommunications Engineer after the graduating 1991 and further received M.Sc. from University St. Cyril and Methodius in 1999. His research interests are in the field of secure public safety communications and PMRN (private mobile radio networks), After his eleven-year career as an engineer and Manager of INFOSEC with the Macedonia's Ministry of Defense, he decided it was time for a change and started working for Ontario's Ministry of Health and Long Term Care and furthermore to the present day with the OntarioGovernment. He is a contributor to academic society, IEEE and ETAI conferences, and member of the IEEE, APCO Canada, MTUG Ontario Chapter and the Professional Engineers of Ontario. Currently resides in Mississauga with his wife and two sons.

Co-Author:

Aleksandar Risteski, Ph.D.

Department of Telecommunications Faculty of Electrical Engineering and Information Technologies, University of St. Cyril and Methodius, Faculty of Electrical Engineering and Information Technologies, Address: Ruger Boskovic 18, 1000 Skopje, Macedonia.

Aleksandar Risteski received his B.Sc., M.Sc. and Ph.D. degrees in telecommunications at the University Ss. Cyril and Methodius, Skopje, Macedonia in 1996, 2000 and 2004, respectively. He is currently a professor and a vice-dean for research and international cooperation at the same university, Faculty of Electrical Engineering and Information Technologies. In 2001, 2003 and 2004, he had several internships at IBM T. J. Watson Research Center, Yorktown Heights, NY, USA, where he worked towards his Ph.D. degree. His research interests are in the field of secure communications, optical communications, and coding theory. He is an author of more than 90 journal and conference papers. He is a mentor of 40 M.Sc. and 6 Ph.D. candidates. Dr. Risteski was a project leader of one bilateral and two national research projects and also a participant in several national, and international projects sponsored by European Commission and IBM. He has also leaded or participated in more than 20 of industry-related R\&D or consultancy projects. He was a member of the National Board for Accreditation and Evaluation of Higher Education in the Republic of Macedonia. From 2009 to 2014 he served as a president of the Society for ETAI (Electronics, Telecommunications, Automation and Informatics) of Republic of Macedonia, co-chaired Conferences ETAI 2009, ETAI 2011, ETAI 2013, and was a co-director of NATO Advanced Research Workshop. From 2005 to 2007, he was an independent member of the Board of Directors of Makedonski telekom AD Skopje. He is also a member of IEEE. 